\title{
KOJŲ ILGIO SKIRTUMO IR ŽMOGAUS PUSIAUSVYROS STABILUMO RYŠYS
}

\author{
Kazimieras Muckus, Vaida Šidlauskaitė, Vilma Juodžbalienė, Vida Česnaitienė \\ Lietuvos kūno kultūros akademija, Kaunas, Lietuva
}

Kazimieras Muckus. Profesorius habilituotas daktaras. Lietuvos kūno kultūros akademijos Taikomosios fiziologijos ir kineziterapijos katedros profesorius. Mokslinių tyrimų kryptis — žmogaus judesių ir fizinių gebėjimų biomechaniniai ypatumai.

\section{SANTRAUKA}

Ar kojų ilgio skirtumas turi ̨takos žmogaus pusiausvyros rodikliams, néra vieningos nuomonès. Šio tyrimo tikslas ištirti, ar koju ilgio skirtumas turi įtakos pusiausvyros stabilumui ir slègio centro padéčiai. Büti tiriami sutiko 22 Lietuvos kūno kultūros akademijos studentai (10 vaikinu ir 12 merginu) nuo 21 iki 25 m. Tiriamieji suskirstyti $\underline{\text { i dvi }}$ grupes: kontroline grupę sudaré 5 tiriamieji. Ju koju ilgis buvo vienodas. Eksperimentinę grupę sudaré 17 skirtingo koju ilgio asmenu. Ju koju ilgio skirtumas buvo nuo -28 mm (trumpesné kairè) iki +8 mm (trumpesnè dešiné). Stabilograma (slègio centro koordinačiu kitimo kreives strèlinèje ir skersinejje ašyse) registravome jëgos plokšte ir kompiuterine iranga analizavome registruojamus signalus. Registruojamo signalo diskretizacija 10 ms. Stabilogramos

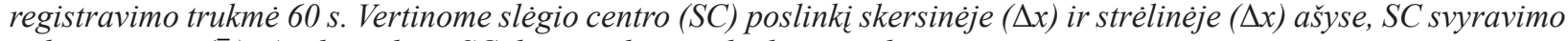
vidutini greiti $(\bar{v})$. Analizuodami SC dažni taikème vilneliu metoda.

Kontrolinès grupès tiriamuju stabilograma registravome tiriamajam stovint 4 pozomis: ant abieju suglaustu koju atmerktomis akimis, nuleistomis rankomis; kūno svorị perkèlus ant dešinès kojos; kūno svori perkèlus ant kairès kojos; po kaire koja padejus $2 \mathrm{~cm}$ medini padq. Eksperimentinès grupés tiriamuju stabilograma registravome jiems stovint ant abieju koju atmerktomis ir užmerktomis akimis ir po trumpesne koja padejus atitinkamo storio medini padq.

Kontrolinès grupès tiriamuju SC svyravimu dydžiai stovint skirtingomis pozomis reikšmingai nesiskyrè. Lyginant su iprasta stovésena ant abieju koju, svorio centra perkèlus ant dešinès ar kairès kojos, SC pasislenka link atraminès kojos. Eksperimentinès grupès tiriamuju SC svyravimu dydžiai reikšmingai skyrèsi jiems stovint atmerktomis ir užmerktomis akimis, tačiau nepriklausè nuo kojų ilgio skirtumo. Kontrolinès ir eksperimentinés grupés stabilometriniai dydžiai tiriamiesiems stovint atmerktomis akimis reikšmingai nesiskyrè.

Išvados: a) koju ilgio skirtumas neturi įtakos žmogaus kūno slègio centro svyravimams, t. y. pusiausvyros stabilumui; b) pado padejimas po koja nesutrikdo pusiausvyros, bet paslenka SC link kitos kojos.

Raktažodžiai: koju ilgio skirtumas, stabilografija, pusiausvyros stabilumas.

\section{IVADAS}

$\mathrm{D}$ augumos žmonių kojų ilgis skiriasi daugiau nei $6 \mathrm{~mm}$. Aišku, jie prisitaiko prie tokio skirtumo ir nejaučia jokių ligos požymių. Deja, kai kuriems žmonėms kojų ilgio skirtumas gali būti nugaros ar kryžmens srities skausmo priežastis arba sukelti klubo, kelio ar pèdos problemomų. Nors kai kurie žmonès prisitaiko prie kojų ilgio skirtumo (iki $20 \mathrm{~mm}$ ), daugumai jau penkių milimetrų skirtumas sukelia judèjimo nepatogumų (Gross, 2007). Žmogaus kūno segmentų nesimetrinè apkrova dèl skirtingo kojų ilgio gali sukelti nugaros ir kojų raumenu tonini susitraukimą (Abate et al., 2010). Kaip teigia B. Gurney (2002), koju ilgio skirtumas veikia ejjimo ir bègimo mechaninius ypatumus, stovėsena, laikysenos svyravimus, taip pat didina skolioziu, osteoartritu, 


\begin{tabular}{|c|c|c|c|c|c|c|c|}
\hline Sando Nr. & 1 & 2 & 3 & 4 & 5 & 6 & $\begin{array}{l}1 \text { lentelè. SC padèties } \\
\text { signalo dažnio cha- }\end{array}$ \\
\hline Dažnis, Hz & $2,5 \div 5,0$ & $1,25 \div 2,5$ & $0,625 \div 1,25$ & $0,312 \div 0,625$ & $0,156 \div 0,312$ & $0,078 \div 0,156$ & \\
\hline
\end{tabular}

kojų kaulų lūžių riziką. Asmenims, kurių kojų ilgio skirtumas yra didelis, siūloma pakelti kulną ar visą koją dèvint avalynę su pakulne.

Ar kojų ilgio skirtumas turi ittakos žmogaus pusiausvyros rodikliams, nèra vieningos nuomonès. R. K. Mahar ir kt. (1985) teigia, kad dirbtinis kojų ilgio skirtumas sutrikdo pusiausvyros kontrolę. Tuo tarpu P. Murrell ir kt. (1991) irodè, kad tarp vienodo ir skirtingo kojų ilgio asmenų nèra pusiausvyros kontrolès skirtumo.

Šio tyrimo tikslas - ištirti, ar kojų ilgio skirtumas turi itakos pusiausvyros stabilumui ir slègio centro padèčiai.

\section{TYRIMO METODIKA}

Savo noru buvo tiriami 22 Lietuvos kūno kultūros akademijos studentai (10 vaikinų ir 12 merginų) nuo 21 iki $25 \mathrm{~m}$. Tiriamieji suskirstyti ị dvi grupes: kontrolinę sudare 5 tiriamieji (jų kojų ilgis buvo vienodas), eksperimentinę - 17 skirtingo kojų ilgio asmenų (jų kojų ilgio skirtumas buvo nuo $-28 \mathrm{~mm}$ (trumpesnè kairè) iki $+8 \mathrm{~mm}$ (trumpesnè dešinè)). Tiriamujų kojų ilgis buvo matuojamas centimetrine juostele. Atlikti trys vienos kojos matavimai ir išvedamas rezultatu vidurkis. Koja buvo matuojama nuo priekinio viršutinio klubakaulio dyglio iki vidinès kulkšnies.

Kontrolinès grupès tiriamuju stabilogramą registruota tiriamajam stovint 4 pozomis:

- ant abiejų kojų atmerktomis akimis. Kojos suglaustos, rankos nuleistos (S 1);

- kūno svoris perkeltas ant dešinès kojos (S 2);

- kūno svoris perkeltas ant kairès kojos (S 3);

- po kaire koja padètas $2 \mathrm{~cm}$ medinis padas (S 4).

Eksperimentinès grupès tiriamujų stabilograma registruota tokiomis pozomis:

- stovint ant abiejų kojų atmerktomis akimis - kojos suglaustos, rankos nuleistos;

- stovint ant abiejų kojų užmerktomis akimis;

- po trumpesne koja padetas atitinkamo storio medinis padas, akys atmerktos;

- tas pat, tik akys užmerktos.

Stabilograma (slègio centro koordinačiu kitimo kreivès strėlinejje ir skersinèje ašyse) registruota jègos plokšte bei registruojamų signalų analizès kompiuterine įranga (Muckus ir kt., 2009). Registruojamo signalo diskretizacija $10 \mathrm{~ms}$. Stabilogra- mos registravimo trukmè $60 \mathrm{~s}$. Vertinome slègio centro (SC) poslinki skersinèje $(\Delta x)$ ir strèlinèje $(\Delta y)$ ašyje, $\mathrm{SC}$ svyravimo vidutini greiti $(\bar{v})$.

SC padèti nusakantis signalas yra stochastinis, tačiau žinomi ir atskirų bendrosios sistemos sandų veiklos signalo dedamuju dažniniai ypatumai. Todèl šio signalo laiko ir dažnio rodikliai rodo atskiru sistemos dalių veikimą. Diskretinè vilnelių transformacija, naudojant Daubechie šeimos 4 eilès vilneles (Mallat, 1999), taikyta SC padèties signalo dekompozicijai nustatyti. Išskirti 6 skirtingų dažnių spektro juostų signalo sandai (1 lent.).

SC padeties signalas, kaip ir jo sandai, anot B. P. Mulgrew ir kt. (1998), yra galios signalas (jo integralas intervalu nuo $-\infty$ iki $\infty$ yra begalinis). Todèl kiekvieno sando galia buvo lygi:

$$
P_{S}=\frac{1}{N} \sum_{i=0}^{N-1}\left|s_{i}-M_{S}\right|^{2},
$$

čia $s_{i}$ - eilinis $\mathrm{S}$ sando atskaitymas, $M_{S}$ - šio sando vidurkis.

Analizuodami duomenis naudojome programini paketą MS Office EXCEL 2000. Kojų ilgio skirtumo ir SC poslinkio tiesinè priklausomybè buvo vertinama Pirsono (Pearson) koreliacijos koeficientu. Nulinè hipotezè apie koreliacijos koeficiento lygybę nuliui ir vidurkių lygybę skirtingomis sąlygomis pagal dviejų veiksnių dispersinę analizę atmetama, kai $\mathrm{p}<0,05$.

\section{REZULTATAI}

Kontrolinès grupès SC svyravimų dydžiai tiriamiesiems stovint skirtingomis pozomis parodyta 1 paveiksle. SC svyravimų dydžių vertė reikšmingai nesiskyrè registruojant stabilogramą tiriamajam stovint skirtingomis pozomis.

2 A paveiksle parodytas SC svyravimu skersinèje ašyje sando galios kitimas, $2 \mathrm{~B}$ - strèlinèje ašyje. Kaip matyti iš pateiktų rezultatų, $\mathrm{SC}$ svyravimų rodikliai reikšmingai nesiskiria, kai stabilograma registruojama tiriamajam stovint skirtingomis pozomis.

Eksperimentinès grupès SC svyravimų dydžiai tiriamiesiems stovint skirtingomis pozomis parodyta 3 paveiksle. Tiriamajam laisvai stovint užmerktomis akimis, reikšmingai padidèjo SC poslinkis skersinejje ašyje nuo 22,3 $\pm 22,34$ iki 27,2 \pm $2,13 \mathrm{~mm}$ ir SC judejjimo vidutinis greitis nuo 
1 pav. Kontrolinės grupès tiriamųjų SC svyravimų dydžiai

Pastaba. $\Delta \mathrm{x}-\mathrm{SC}$ poslinkis skersinèje ašyje (mm), $\Delta \mathrm{y}$ - strèlinèje ašyje, $\bar{v}-\mathrm{SC}$ svyravimo vidutinis greitis $(\mathrm{mm} / \mathrm{s})$. S 1 - stovèsena ant abiejų kojų, S 2 - kūno svoris ant dešinès kojos, S 3 - svoris ant kairès kojos, $\mathrm{S} 4-2 \mathrm{~cm}$ padas po kaire koja. Parodyta: vidurkis \pm standartine paklaida.

2 pav. Kontrolinès grupės SC svyravimu skersinèje (A) ir strèlinèje (B) ašyje sandụ galia stabilogramą registruojant tada, kai tiriamasis stovi skirtingomis pozomis

Pastaba. Žymèjimai kaip 1 pav.

3 pav. Eksperimentinès grupès SC svyravimų dydžiai tiriamiesiems stovint skirtingomis pozomis

Pastaba. 1 - akys atmerktos; 2 - akys užmerktos; 3 - akys atmerktos, po trumpesne koja padètas padas; 4 - akys užmerktos, po trumpesne koja padetas padas. Parodyta: vidurkis \pm standartine paklaida.
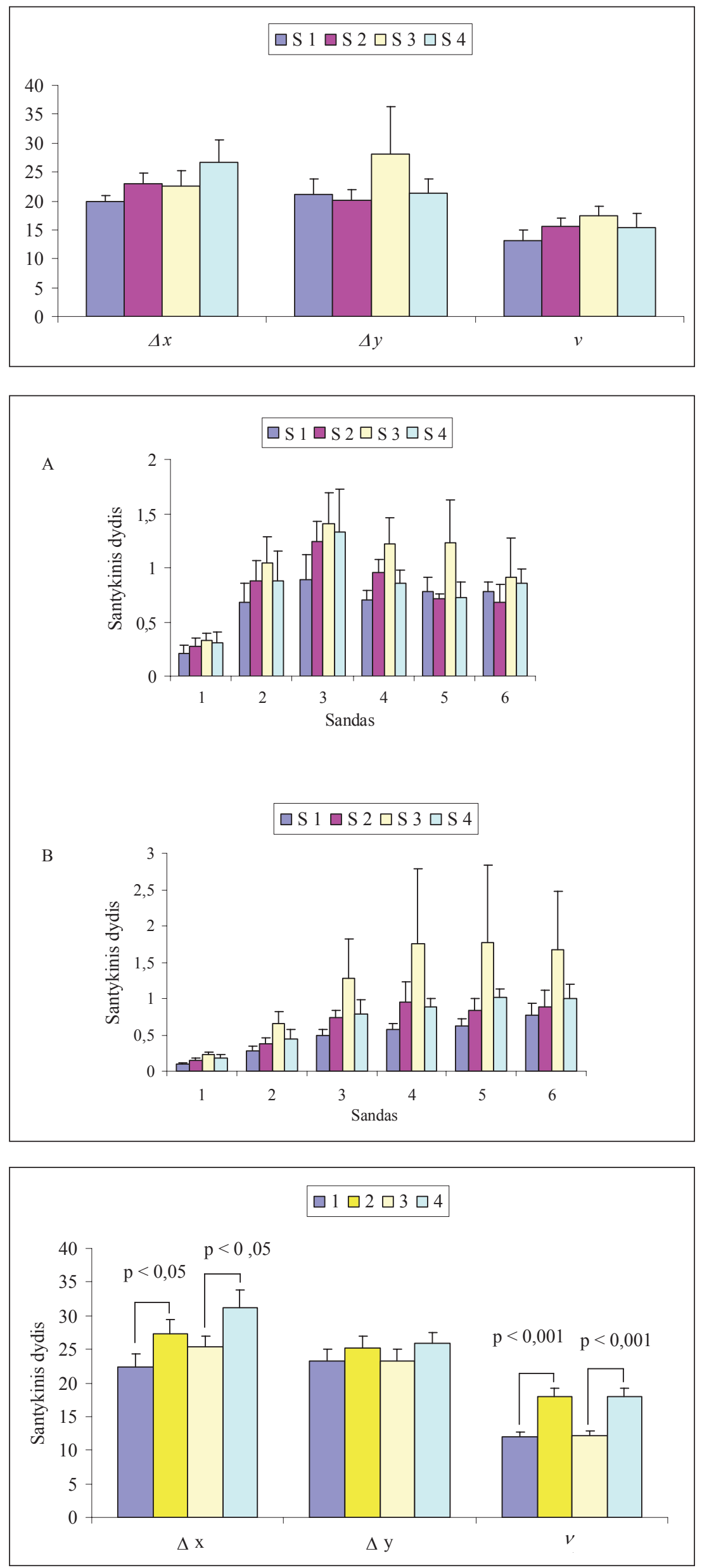

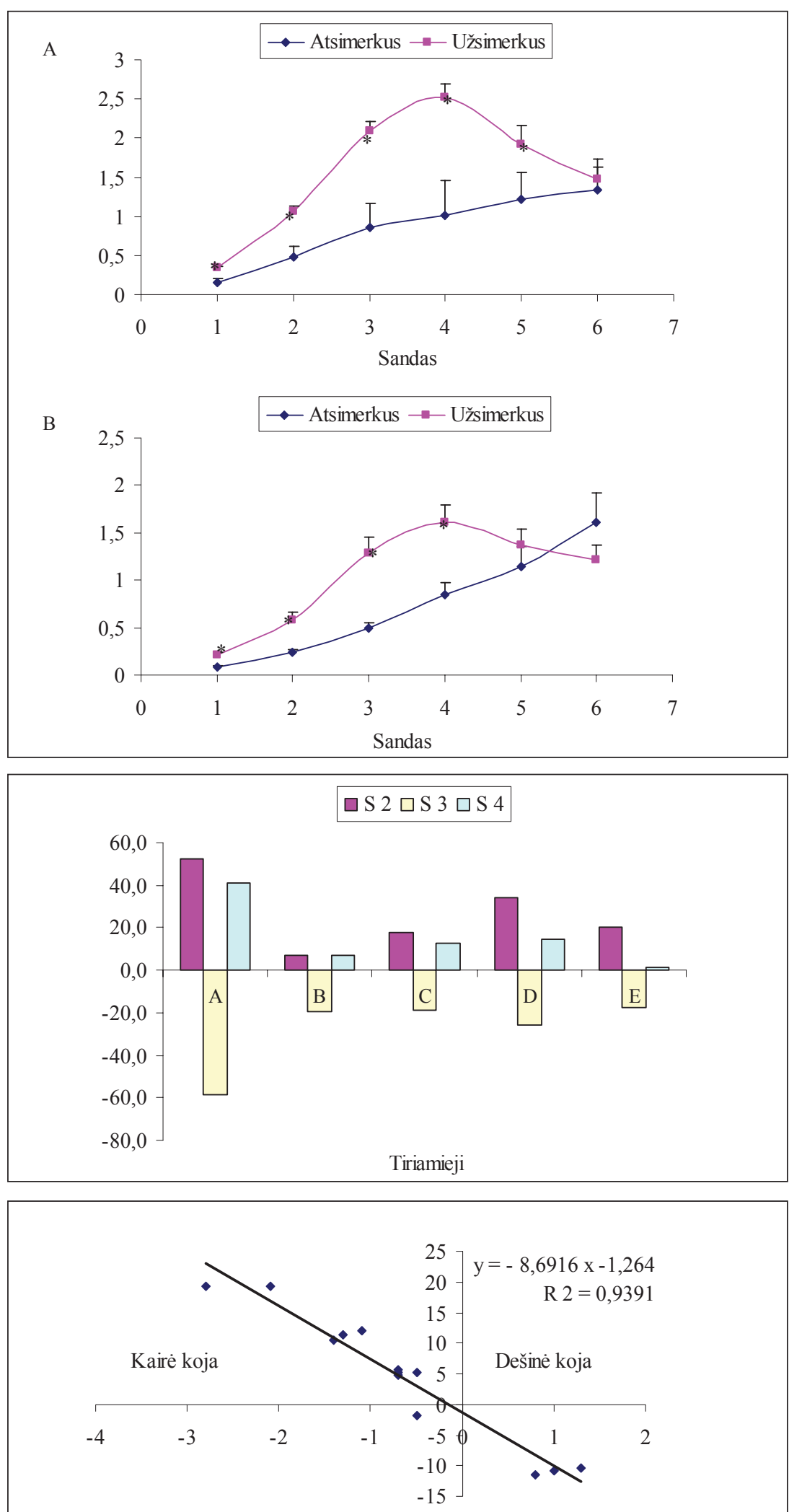

Kojų ilgio skirtumas, cm
4 pav. Eksperimentinès grupès SC svyravimo skersinėje (A) ir strèlinėje (B) ašyje sando galios kitimas tiriamiesiems stovint atmerktomis ir užmerktomis akimis

Pastaba. Parodyta: vidurkis \pm standartine paklaida. ${ }^{*}-\mathrm{p}<0,001$

5 pav. Kontrolinės grupės tiriamujụ $(A, B$, $\mathrm{C}, \mathrm{D}, \mathrm{E}) \mathrm{SC}$ pasislinkimas skersinėje ašyje (mm), lyginant su iprasta stovèsena ant abiejų kojų, svorị paskirsčius tolygiai

Pastaba. S 2 - svoris ant dešinès kojos, S 3 - ant kairès kojos, $\mathrm{S} 4-2 \mathrm{~cm}$ padas po kaire koja.

6 pav. Ordinačių ašyje - SC pasislinkimas skersinėje ašyje, padėjus atitinkamo storio padą po trumpesne tiriamojo koja
$12,0 \pm 0,73$ iki $18,0 \pm 1,15 \mathrm{~mm} / \mathrm{s}$ ( 1 ir 2 pozos $)$. Kai po trumpesne koja padètas atitinkamo storio medinis padas, pokyčiai tiriamajam užmerkus akis yra panašūs: $\Delta x$ reikšmingai padidejo nuo $25,4 \pm$ 1,45 iki $31,24 \pm 2,59 \mathrm{~mm}, \bar{v}-$ nuo $12,1 \pm 0,67$ iki $17,92 \pm 1,20 \mathrm{~mm} / \mathrm{s}$ ( 3 ir 4 pozos). Svyravimai strèlinejje ašyje tiriamajam esant atmerktomis ir užmerktomis akimis reikšmingai nesiskyrè.

SC svyravimų dažnių analizė parodè, kad svyravimai skersinejje ir strèlinejje ašyje tiriamajam užsimerkus daugiausia padidejja $0,312-1,25 \mathrm{~Hz}$ dažnių juostoje (3, 4 sandai) (4 pav.). Tai rodo, 
2 lentelè. Kontrolinès ir eksperimentinès grupès stabilometriniai rodikliai tiriamiesiems stovint atmektomis akimis
Pastaba. $x_{i} \mathrm{SG}$ - SC svyravimų skersinėje ašyje sando galia; $y_{i} \quad \mathrm{SG}-\mathrm{SC}$ svyravimu strèlinèje ašyje sando galia; $i$ - sando numeris. Pateikta: vidurkis \pm standartiné paklaida.

\begin{tabular}{|l|c|c|}
\hline & Kontroline & Eksperimentine \\
\hline$\Delta x, \mathrm{~mm}$ & $19,89 \pm 1,049$ & $22,35 \pm 1,945$ \\
\hline$\Delta y, \mathrm{~mm}$ & $21,08 \pm 2,660$ & $23,23 \pm 1,848$ \\
\hline $\bar{v}, \mathrm{~mm} / \mathrm{s}$ & $13,13 \pm 1,804$ & $11,96 \pm 0,732$ \\
\hline$x_{1} \mathrm{SG}$ & $0,21 \pm 0,068$ & $0,16 \pm 0,022$ \\
\hline$x_{2} \mathrm{SG}$ & $0,68 \pm 0,175$ & $0,48 \pm 0,061$ \\
\hline$x_{3} \mathrm{SG}$ & $0,89 \pm 0,229$ & $0,86 \pm 0,122$ \\
\hline$x_{4} \mathrm{SG}$ & $0,70 \pm 0,094$ & $1,02 \pm 0,174$ \\
\hline$x_{5} \mathrm{SG}$ & $0,78 \pm 0,136$ & $1,22 \pm 0,240$ \\
\hline$x_{6} \mathrm{SG}$ & $0,78 \pm 0,083$ & $1,33 \pm 0,255$ \\
\hline$y_{1} \mathrm{SG}$ & $0,10 \pm 0,024$ & $0,09 \pm 0,013$ \\
\hline$y_{2} \mathrm{SG}$ & $0,27 \pm 0,076$ & $0,23 \pm 0,031$ \\
\hline$y_{3} \mathrm{SG}$ & $0,49 \pm 0,077$ & $0,49 \pm 0,057$ \\
\hline$y_{4} \mathrm{SG}$ & $0,58 \pm 0,069$ & $0,85 \pm 0,130$ \\
\hline$y_{5} \mathrm{SG}$ & $0,63 \pm 0,099$ & $1,15 \pm 0,204$ \\
\hline$y_{6} \mathrm{SG}$ & $0,78 \pm 0,164$ & $1,61 \pm 0,310$ \\
\hline
\end{tabular}

kad rega atsakinga už SC svyravimus būtent šioje dažnių juostoje.

Kontrolinès ir eksperimentinès grupès stabilometriniai rodikliai tiriamiesiems stovint atmerktomis akimis reikšmingai nesiskyrè (2 lent.).

Tyrème, kaip kinta kontrolinès grupès tiriamujų SC padètis kūno svorį perkèlus ant kairès ir dešinès kojos, po viena koja padejus $2 \mathrm{~cm}$ padą. Lyginant su iprasta stovėsena ant abiejų kojų, svorio centrą perkèlus ant dešinès ar kairès kojos. SC pasislenka link atraminès kojos (5 pav.). Idomu tai, kad po kaire koja padejus $2 \mathrm{~cm}$ storio padą SC pasislenka dešinès kojos link panašiai tiek pat, kaip ir kūno svori perkèlus ant dešinès.

6 paveiksle parodyta kojų ilgio skirtumo ir SC pasislinkimo skersineje ašyje koreliacinè priklausomybè, po trumpesne koja padejus atitinkamo storio padą. Matyti, kad padejjus padą SC pasislenka link ilgesnès kojos.

\section{REZULTATU APTARIMAS}

Kojų ilgio skirtumas veikia ejjimo ir bėgimo mechanines savybes, stovèsena, laikysenos svyravimus, taip pat padidina skoliozių, osteoartritu, kojų kaulų lūžių riziką (Gurney, 2002). Kojų ilgio skirtumo poveikis žmogaus pusiausvyrai nėra irodytas. R. K. Mahar ir kt. (1985) ištyre 14 savanorių, kurių stabilograma buvo registruojama tiriamiesiems stovint standartine poza ir po viena iš koju padèjus 1, 2, 3 ir $4 \mathrm{~cm}$ padą. Rezultatai parodè, kad padejjus padą SC pasislenka link ilgesnès (po kuria nèra paaukštinimo) kojos, statistiškai patikimai padidèja SC poslinkis skersinèje ašyje, bet nesikeičia strèlinèje.

P. Murrell ir kt. (1991) tyrè 20 savanorių, iš kurių vienuolikos kojų ilgio skirtumas buvo didesnis nei 9,5 mm, devyniu kojos buvo vienodo ilgio. Kontrolinès ir eksperimentinès grupès tiriamuju pusiausvyros rodikliai nesiskyrè, tačiau jie patikimai skyrèsi tiriamiesiems stovint atmerktomis ir užmerktomis akimis.

Išsamiau mes tyrème pusiausvyrą. Matavome ne tik SC poslinkį skersinejje ir strèlinėje ašyje, vidutini judejjimo greiti, bet ir SC svyravimų dažni. Tyrimas parodè, kad tarp nevienodo ir vienodo kojų ilgio asmenu nèra pusiausvyros kontrolès skirtumų. SC svyravimų dažnio analizè atskleidè, kad svyravimai skersinejje ir strèlinèje ašyje tiriamiesiems užsimerkus daugiausia padidèja $0,312-$ $1,25 \mathrm{~Hz}$ dažniu juostoje (3, 4 sandai) (4 pav.). Vadinasi, rega yra atsakinga už SC svyravimus būtent šioje dažniu juostoje. Nors nèra išsamios SC svyravimų dažnio analizès, kai kurie autoriai nurodo, kad svyravimus $0,7-1 \mathrm{~Hz}$ dažnių juostoje lemia regimoji informacija (Giacomini et al., 1998). Mūsų taikytas vilnelių metodas patvirtina minètas prielaidas.

\section{IŠVADOS}

Kojų ilgio skirtumas neturi įtakos žmogaus kūno slègio centro svyravimams, t. y. pusiausvyros stabilumui.

Pado padejjimas po koja nesutrikdo pusiausvyros, bet paslenka SC link kitos kojos. 


\title{
LITERATŪRA
}

Abate, M., Di Carlo, L., Di Romualdo, S. et al. (2010). Postural adjustment in experimental leg length difference evaluated by means of thermal infrared imaging. Physiological Measurement, 31 (1) 35-43.

Giacomini, P., Sorace, F., Margini, A. (1998). Alterations in postural control: The use of spectral analysis in stability measurement. Acta Otorhinolaryngol, 18 (2), 83-7.

Gross, A. B. (2007). Low Back Pain and Leg Length Inequality. Prieiga internetu: http://gwheellift.com/leglength-inequality.html

Gurney, B. (2002). Leg length discrepancy. Gait \& Posture, 15 (2), 195-206.

Mahar, R. K, Kirby, R. L., MacLeod, D. A. (1985). Simulated leg-length discrepancy: Its effect of mean center-of- pressure position and postural sway. Archives of Physical Medicine and Rehabilitation, 66, 822-824.

Mallat, S. G. (1999). A Wavelet Tour of Signal Processing. Academic Press.

Muckus, K., Juodžbalienė, V., Kriščiukaitis, A., Pukėnas, K., Škikas, L. (2009). The gastrocnemius muscle stiffness and human balance stability. Mechanika, 6 (80), 18-22.

Mulgrew, B., Grant, P., Thompson, J. et al. (1998). Digital Signal Processing, Concepts \& Applications. Basingstoke, UK: Palgrave Macmillan.

Murrell, P., Cornwall, M. W., Doucet, S. K. (1991). Leglength discrepancy: Effect on the amplitude of postural sway. Archives of Physical Medicine and Rehabilitation, $72,646-648$.

\section{RELATION BETWEEN DIFFERENCE IN LEG LENGTH AND POSTURAL STABILITY}

\author{
Kazimieras Muckus, Vaida Šidlauskaitė, Vilma Juodžbalienė, Vida Česnaitienė \\ Lithuanian Academy of Physical Education, Kaunas, Lithuania
}

\begin{abstract}
There are a many different views, how the difference in leg length influences the postural stability. The aim of this study was to investigate whether the difference in leg length affects the postural stability and the position of the center of pressure (COP). Twenty two volunteers (10 males, 12 females) between the ages of 21 ant 25 years participated in the trial. Five subjects with no measurable leg length discrepancy constituted the control group. The experimental group consisted of seventeen subjects. Their leg length discrepancy was between $-28 \mathrm{~mm}$ (shorter left leg) to $+8 \mathrm{~mm}$ (shorter right leg). For the analysis of the signals the force plate and software was used to estimate the static posturography. The sampling rate of the signal was $10 \mathrm{~ms}$. The duration of the stabilogram recording was $60 \mathrm{~s}$. The COP dislocation amplitude in transverse and sagittal direction, the mean velocity of COP sways were estimated too.

In the control group each subject stood barefoot on a force platform with their feet together. The subjects stood with their eyes opened and then with their eyes closed, weight transferred on the right foot, weight transferred on the left foot, and with a lift of $2 \mathrm{~cm}$ under their left feet. In the experimental group each subject stood barefoot on a force platform with their feet together. They stood with their eyes opened and then with their eyes closed, and with a lift under the shorter leg. The postural sway data standing in different poses were not significantly different in the control group. Compared to the uprigth standing on both feet, as the center of gravity was moved in the right or left foot, COP moved toward the bearing leg. COP postural sway values of the experimental group subjects were significantly different standing with eyes opened and with eyes closed, but independent by of leg length difference. There were no significant difference in stabilometric data in standing with eyes opened and eyes closed between the control and the experimental groups.

It may be occluded that: a) subjects with a leg length difference do not have more postural sway than those without any difference in leg length, b) lift placement of the foot did not disturb the balance, but transfered COP toward other leg.
\end{abstract}

Keywords: difference in leg length, stabilography, postural stability.

Gauta 2009 m. lapkričio 11 d.

Received on November 11, 2009

Priimta $2010 \mathrm{~m}$. vasario $4 \mathrm{~d}$.

Accepted on February 4, 2010
Kazimieras Muckus

Lietuvos kūno kultūros akademija

(Lithuanian Academy of Physical Education)

Sporto g. 6, LT-44221 Kaunas

Lietuva (Lithuania)

Tel +37037302635

E-mail k.muckus@1kka.lt 